\title{
Beneficial Effects of Teucrium polium and Metformin on Diabetes-Induced Memory Impairments and Brain Tissue Oxidative Damage in Rats
}

\author{
S. Mojtaba Mousavi, ${ }^{1}$ Saeed Niazmand, ${ }^{1}$ Mahmoud Hosseini, ${ }^{2}$ Zarha Hassanzadeh, \\ Hamid Reza Sadeghnia, ${ }^{3}$ Farzaneh Vafaee, ${ }^{1}$ and Zakieh Keshavarzi ${ }^{4}$ \\ ${ }^{1}$ Neurogenic Inflammation Research Center, School of Medicine, Mashhad University of Medical Sciences, Mashhad 9177948564, Iran \\ ${ }^{2}$ Neurocognitive Research Center, School of Medicine, Mashhad University of Medical Sciences, Mashhad 9177948564, Iran \\ ${ }^{3}$ Pharmacological Research Center of Medicinal Plants, School of Medicine, Mashhad University of Medical Sciences, \\ Mashhad 9177948564, Iran \\ ${ }^{4}$ Department of Physiology, School of Medicine, North Khorasan University of Medical Sciences, Bojnourd, Iran
}

Correspondence should be addressed to Mahmoud Hosseini; hosseinim@mums.ac.ir

Received 28 September 2014; Revised 1 January 2015; Accepted 26 January 2015

Academic Editor: John Powell

Copyright (C) 2015 S. Mojtaba Mousavi et al. This is an open access article distributed under the Creative Commons Attribution License, which permits unrestricted use, distribution, and reproduction in any medium, provided the original work is properly cited.

Objective. The effects of hydroalcoholic extract of Teucrium polium and metformin on diabetes-induced memory impairment and brain tissues oxidative damage were investigated. Methods. The rats were divided into: (1) Control, (2) Diabetic, (3) Diabetic-Extract 100 (Dia-Ext 100), (4) Diabetic-Extract 200 (Dia-Ext 200), (5) Diabetic-Extract 400 (Dia-Ext 400), and (6) Diabetic-Metformin (Dia-Met). Groups 3-6 were treated by 100, 200, and $400 \mathrm{mg} / \mathrm{kg}$ of the extract or metformin, respectively, for 6 weeks (orally). Results. In passive avoidance test, the latency to enter the dark compartment in Diabetic group was lower than that of Control group $(P<0.01)$. In Dia-Ext 100, Dia-Ext 200, and Dia-Ext 400 and Metformin groups, the latencies were higher than those of Diabetic group $(P<0.01)$. Lipid peroxides levels (reported as malondialdehyde, MDA, concentration) in the brain of Diabetic group were higher than Control $(P<0.001)$. Treatment by all doses of the extract and metformin decreased the MDA concentration $(P<$ 0.01). Conclusions. The results of present study showed that metformin and the hydroalcoholic extract of Teucrium polium prevent diabetes-induced memory deficits in rats. Protection against brain tissues oxidative damage might have a role in the beneficial effects of the extract and metformin.

\section{Introduction}

Diabetes is a growing problem throughout the world. The global prevalence of established diabetes is estimated to be $2.8 \%$ in 2000 and is predicted to be $4.4 \%$ by 2030 [1]. Diabetes generates a variety of functional and structural disturbances in the different organs especially central and peripheral nervous systems [2, 3]. Moreover, a wide range of learning and memory impairments have been observed in adults with diabetes mellitus [4-6]. Electrophysiological and structural abnormalities of the brain of diabetic subjects have also been reported [3]. Diabetes also conceivably leads to cognitive impairments through chronic hyperglycemia [7].
It has been well documented that oxidative stress plays a pivotal role in the development of diabetes complications, including learning and memory impairments $[8,9]$. Enhanced formation of oxygen free radicals occurs in tissues during hyperglycemia. These oxidant radicals contribute to increased neuronal death in many brain regions such as the hippocampus, through protein oxidation, DNA damage, and peroxidation of membrane lipids [10].

The medicinal use of plants dates back to ancient times. Teucrium polium L. (Lamiaceae) has been used for over 2000 years in traditional medicine due to its diuretic, diaphoretic, tonic, antipyretic, antispasmodic, and cholagogic properties [11]. In addition, the plant possesses hypoglycemic, 
hypolipidemic, insulinotropic, antioxidant, antinociceptive, and anti-inflammatory properties [12-15]. It also affects cardiovascular system [16], reduces body weight [17], protects against acetaminophen-induced hepatotoxicity [18-21], and improves cognitive deficits [22].

Considering these beneficial effects of Teucrium polium, the objective of this study was to investigate the effects of long-term oral administration of Teucrium polium and metformin on learning and memory impairments in diabetic rats using a passive avoidance test. Markers of oxidative stress, mainly, lipid peroxides levels (reported as malondialdehyde, $\mathrm{MDA}$ ) and total thiol (SH) content, were also measured in cortical and hippocampal regions.

\section{Materials and Methods}

2.1. Preparing the Plant Extract. Teucrium polium was collected from Nishabur City, Khorasan Province, Iran, and identified by botanists in Ferdowsi University of Mashhad, Iran, and a voucher specimen was deposited. The plants were then dried at room temperature. To prepare the hydroalcoholic extract, $50 \mathrm{~g}$ of the chopped and dried aerial parts of the plant was soaked in ethanol (50\%) for $48 \mathrm{~h}$ and filtered through paper filter. The extract was then dried with rotary vacuum evaporator.

2.2. Animals and the Experimental Protocol. Male Wistar rats (10 weeks old and weighing $250 \pm 20 \mathrm{~g}$ ) were kept at $22 \pm 2^{\circ} \mathrm{C}$ and $12 \mathrm{~h}$ light/dark cycle at 7:00 a.m. They were randomly divided into six groups and treated according to the experimental protocol:

(1) Control, (2) Diabetic, (3) Diabetic-Extract 100 (DiaExt 100), (4) Diabetic-Extract 200 (Dia-Ext 200), (5) Diabetic-Extract 400 (Dia-Ext 400), and (6) Diabetic-Metformin (Dia-Met). Diabetes was induced in groups $2-6$ by a single intraperitoneal (i.p.) injection of streptozotocin $(55 \mathrm{mg} / \mathrm{kg})$ [23]. The animals of groups 3-5 were orally treated by 100 , 200 , and $400 \mathrm{mg} / \mathrm{kg}$ of the extract for 6 weeks. The animals of Dia-Met group were treated by metformin (300 mg/kg) [24]. The treatments by the extract or metformin were started 72 hours after STZ injection. The extract and metformin were dissolved in saline. Only the animals with serum glucose higher than $250 \mathrm{mg} / \mathrm{dL}$ at $72 \mathrm{~h}$ after streptozotocin injection were included in the study. All efforts were made to maintain the animals in good general health, in accordance with the European Communities Council Directive (2010/63/UE). Animal handling and all related procedures were confirmed by Mashhad University of Medical Sciences, Ethical Committee.

2.3. Passive Avoidance Test. The passive avoidance learning test based on negative reinforcement was carried out. The apparatus had a grid floor and comprised two compartments: one dark and the other one lighted, with a small gate which connected these two parts. This test is performed with the knowledge that rats have a native preference for the dark environment. Before beginning the training sessions, the animals were familiarized with the apparatus for two successive days ( 5 min per day). On the ensuing day, they were placed in the lighted compartment and the time latency for entering the dark compartment and the time spent in dark and light compartments were noted down. During the training phase, the animals were located in the lighted compartment while they were facing the walls and away from the gate and they received an electric shock (1.5 mA, $2 \mathrm{~s}$ duration) when they were entered the dark part. The animals were then returned to their cages. In retention or test phase, which was carried out at one hour and twenty-four hours after the training session, the rats were placed in the light compartment, and time latency to enter the dark compartment and the time spent by the animals in the dark and light compartments were recorded [25]. All behavioral tests were conducted between 16:00 and 18:00 o'clock.

2.4. Biochemical Assessments. After the behavioral study, blood samples were collected for determination of serum glucose level, the animals were then sacrificed, and the brains were removed and dissected on an ice-cold surface and conserved for biochemical measurements.

Total SH groups were measured using DTNB $\left(2,2^{\prime}\right.$-dinitro-5, $5^{\prime}$-dithiodibenzoic acid) as the reagent. This reagent reacts with the $\mathrm{SH}$ groups to produce a yellow colored complex which has a peak absorbance at $412 \mathrm{~nm}$. Briefly, $1 \mathrm{~mL}$ Tris-EDTA (ethylenediaminetetraacetic acid) buffer $(\mathrm{pH}=8.6)$ was added to $50 \mu \mathrm{L}$ brain homogenate in $1 \mathrm{~mL}$ cuvettes and sample absorbance was read at $412 \mathrm{~nm}$ against Tris-EDTA buffer alone $\left(A_{1}\right)$. Then $20 \mu \mathrm{L}$ DTNB reagents (10 $\mathrm{mM}$ in methanol) were added to the mixture and after $15 \mathrm{~min}$ (at laboratory temperature) the sample absorbance was read again $\left(A_{2}\right)$. The absorbance of DTNB reagent was also read as a blank $(B)$. Total thiol concentration $(\mathrm{mM})$ was calculated from the following equation [26-28]:

Total thiol concentration $(\mathrm{mM})$

$$
=\left(A_{2}-A_{1}-B\right) \times \frac{1.07}{0.05} \times 13.6 .
$$

Malondialdehyde (MDA) levels, as an index of lipid peroxidation, were also measured. MDA reacts with thiobarbituric acid (TBA) as a thiobarbituric acid reactive substance (TBARS) to produce a pink colored complex which has peak absorbance at $535 \mathrm{~nm}$. $2 \mathrm{~mL}$ of TBA/TCA (trichloroacetic acid)/HCL (hydrochloric acid) reagent was added to $1 \mathrm{~mL}$ of homogenate and the solution was heated in a water bath for $40 \mathrm{~min}$. After cooling, the solution was centrifuged at $1000 \mathrm{~g}$ for $10 \mathrm{~min}$. The absorbance was measured at $535 \mathrm{~nm}$. The MDA concentration was calculated as follows: $C(\mathrm{~m})=$ Absorbance/ $\left(1.65 \times 10^{5}\right)[27,28]$.

2.5. Statistical Analysis. The data were expressed as mean \pm SEM. One-way ANOVA was run followed by Tukey's post hoc test comparisons test (SPSS 11.5 software). The criterion for the statistical significance was $P<0.05$.

\section{Results}

3.1. Passive Avoidance Test. In the Diabetic group, the time latency for entering the dark compartment was lower than 


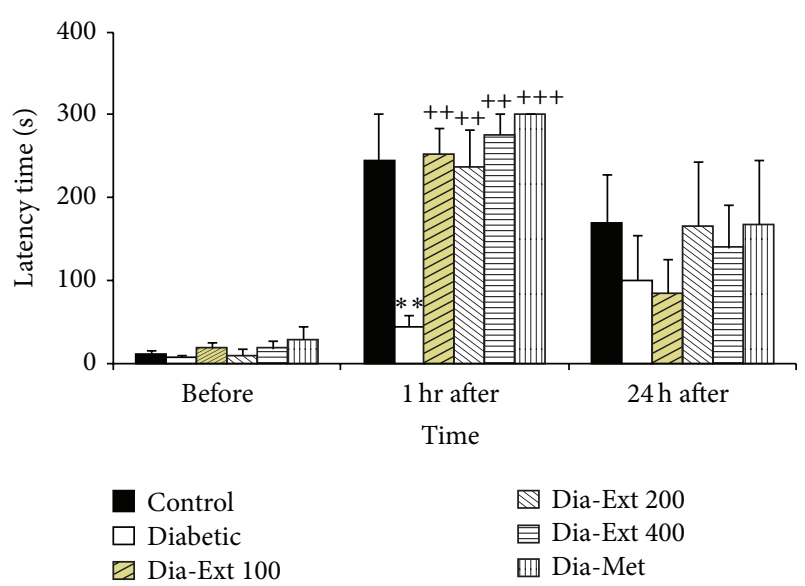

FIGURE 1: Comparison of time latency for entering the dark compartment before and at 1 and $24 \mathrm{~h}$ after receiving the shock in the experimental groups. Data are presented as mean \pm SEM $(n=10$ in each group). ${ }^{* *} P<0.01$ in comparison with Control group and ${ }^{++} P<0.01$ and ${ }^{+++} P<0.001$ in comparison with Diabetic group.

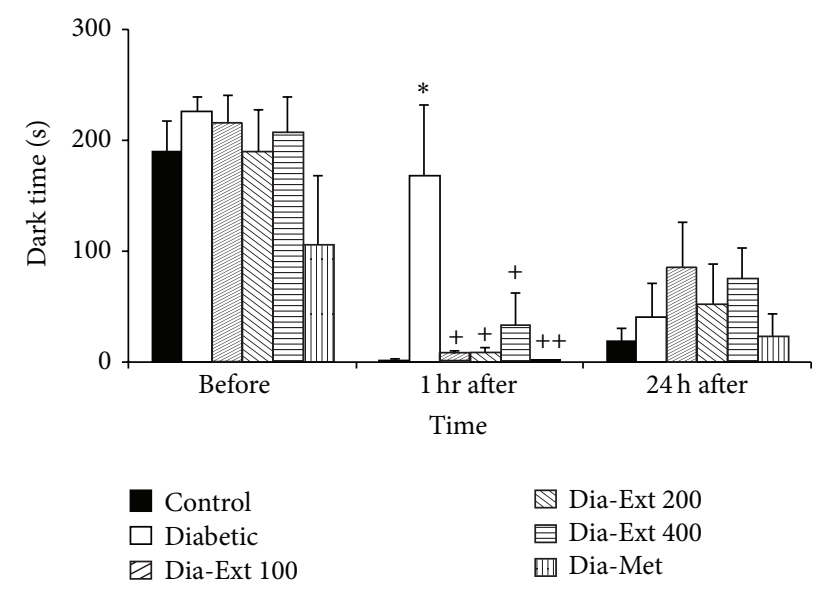

Figure 2: Comparison of the total time spent in the dark compartment before and at 1 and $24 \mathrm{~h}$ after receiving the shock in the experimental groups. Data are presented as mean \pm SEM $(n=10$ in each group). ${ }^{*} P<0.05$ in comparison with Control group and ${ }^{+} P<0.05$ and ${ }^{++} P<0.01$ in comparison with Diabetic group.

that of the Control group, $1 \mathrm{~h}$ after shock (Figure 1, $P<0.01$ ). The treatment of the animals by 100,200 , and $400 \mathrm{mg} / \mathrm{kg}$ of Teucrium polium extract significantly increased the time latency for entering the dark compartment at $1 \mathrm{~h}$ after receiving a shock (Figure $1, P<0.01$ ). Treatment by metformin also increased the time latency for entering the dark compartment at $1 \mathrm{~h}$ after receiving a shock. There were no significant differences between groups at 24 hours after shock (Figure 1).

One hour after receiving the shock, the total time spent in the dark compartment by the animals of the Diabetic group was more than that of the Control group (Figure 2, $P<0.05$ ). Treatment by all three doses of the extract decreased the total time spent in dark compartment at 1 hour after receiving the shock (Figure 2, $P<0.05$ ). The total time spent in the dark
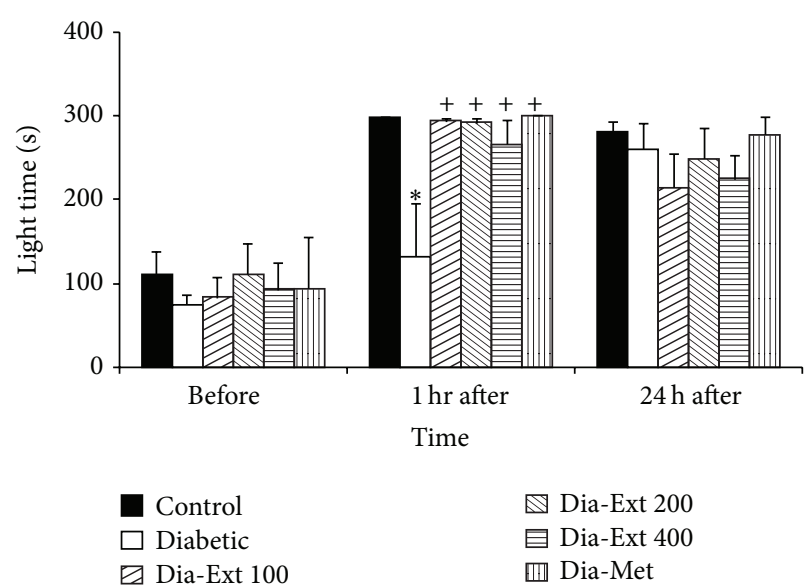

Figure 3: Comparison of the total time spent in the light compartment before and at 1 and $24 \mathrm{~h}$ after receiving the shock in the experimental groups. Data are presented as mean \pm SEM $(n=10$ in each group). ${ }^{*} P<0.05$ in comparison with Control group and ${ }^{+} P<0.05$ in comparison with Diabetic group.

compartment by the animals of Dia-Met group was lower than that of the Diabetic group (Figure 2, $P<0.01$ ).

The results also showed that the time spent in the light compartment by the animals of the Diabetic group was lower than that of the Control group at $1 \mathrm{~h}$ after receiving the shock (Figure 3, $P<0.05$ ); however, there was no significant difference at $24 \mathrm{~h}$ after the shock. Treatment of the animals by $100-400 \mathrm{mg} / \mathrm{kg}$ of the extract and metformin increased the time spent in the light compartment when the animals were examined at $1 \mathrm{~h}$ after receiving a shock (Figure 3 ). There were no significant differences between groups at $24 \mathrm{~h}$ after the shock.

3.2. Biochemical Assessment Results. MDA concentration in hippocampal tissues of the Diabetic group was higher than Control ones (Figure 4(a); $P<0.001$ ). Pretreatment of the animals by 100,200 , and $400 \mathrm{mg} / \mathrm{kg}$ of the extract decreased the MDA concentration in the hippocampal tissues in the Diabetic group (Figure 4(a); all $P<0.001$ ). Treatment of diabetic rats by metformin also reduced MDA concentration in hippocampal tissues (Figure 4(a); all $P<0.001$ ).

The total thiol concentration in hippocampal tissues of the Diabetic group was significantly lower than Control animals (Figure 4(b); $P<0.05$ ). In Dia-Met group, the hippocampal total thiol concentrations were significantly higher than that of the Diabetic group (Figure 4(b); $P<0.01$ ); however, treatment with the extract with doses of $100-400 \mathrm{mg} / \mathrm{kg}$ was not effective in reducing total thiol concentrations.

The results also showed that cortical MDA concentration in Diabetic group was significantly higher than Control group (Figure 5(a); $P<0.001$ ). In cortical tissues of Dia-Ext 100, Dia-Ext 200, and Dia-Ext 400 groups, MDA concentrations were lower than that of Diabetic group (Figure 5(a); $P<0.01$ and $P<0.001)$. The animals of Dia-Met group also had a lower MDA concentration in cortical tissues when compared with Diabetic group (Figure 5(a); $P<0.01$ ). 


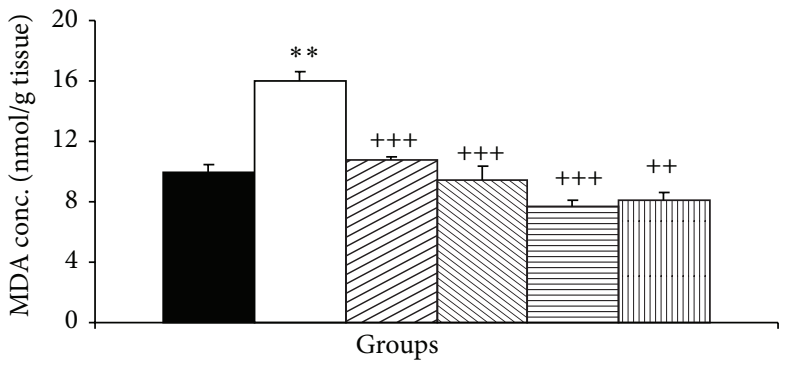

Control $\square$ Diabetic $\square$ Dia-Ext 100

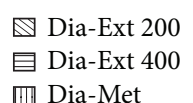

미 Dia-Met

(a)

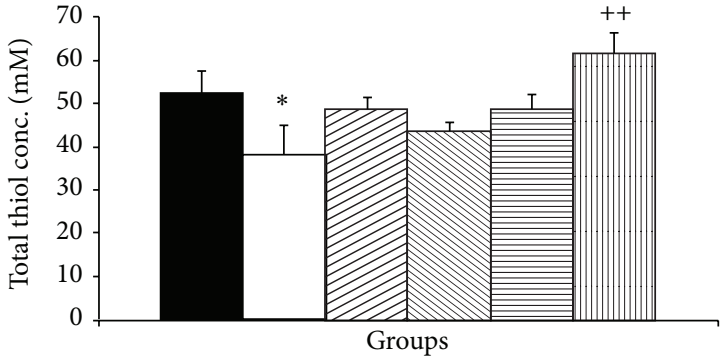

$\square$ Control
$\square$ Diabetic $\square$ Dia-Ext 100

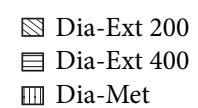

(b)

FIGURE 4: The MDA concentrations (a) and total thiol concentrations (b) in hippocampal tissues of 6 groups. Data are shown as mean \pm SEM of 10 animals per group. ${ }^{*} P<0.05$ and ${ }^{* * *} P<0.001$ in comparison with Control group and ${ }^{++} P<0.01$ and ${ }^{+++} P<0.001$ in comparison with Diabetic group.

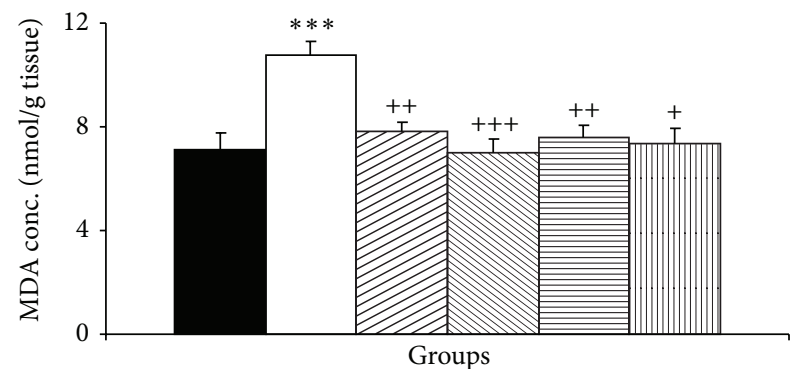

Control $\square$ Diabetic $\square$ Dia-Ext 100

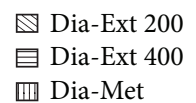

血 Dia-Met

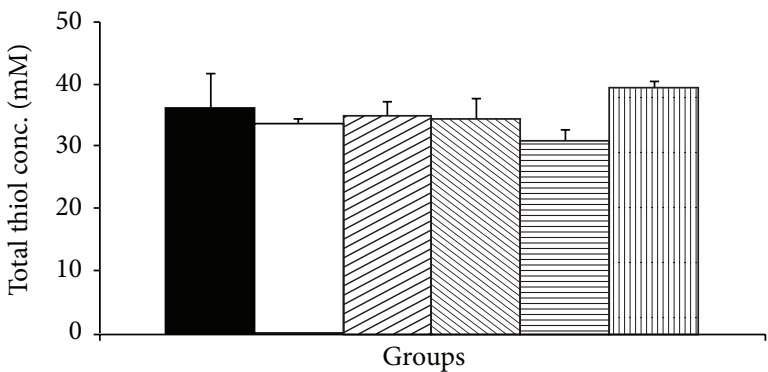

- Control $\square$ Diabetic $\square$ Dia-Ext 100

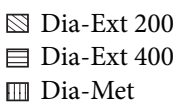

III) Dia-Met

(a)

(b)

Figure 5: The MDA concentrations (a) and total thiol concentrations (b) in cortical tissues of 6 groups. Data are shown as mean \pm SEM of 10 animals per group. ${ }^{* * *} P<0.001$ in comparison with Control group and ${ }^{++} P<0.01$ and ${ }^{+++} P<0.001$ in comparison with Diabetic group.

As shown in Figure 5(a), the total thiol concentration in cortical tissues of the Diabetic group was lower than from Control group (Figure 5(b)). Administration of the extract did not affect the total thiol concentration (Figure 5(b)). Metformin nonsignificantly increased the total thiol concentration in cortical tissues.

Blood glucose concentration in the Diabetic group was significantly higher than Control group (Figure 6; $P<0.01$ ). Administration of the extract did not affect the glucose concentration (Figure 6). Metformin nonsignificantly reduced the blood glucose concentration.

\section{Discussion}

The present study demonstrated that chronic hyperglycemia in diabetic rats significantly impaired learning and memory. Treatment with the different doses of Teucrium polium for 6 weeks improved the deleterious effects of diabetes on learning and memory. Consistent with our results, learning deficits have been shown in streptozotocin-induced diabetic rats in Morris water maze [29]. Evidence is accumulating that people with diabetes mellitus are at risk of developing cognitive impairments [30,31]. It has also been demonstrated that acute hyperglycemia in people with type 2 diabetes significantly impaired speed of information processing, working memory, and some aspects of attention [31]. This deficiency in learning and memory has been suggested to be associated with the changes in hippocampal synaptic plasticity $[9,32]$. It has also been suggested that oxidative stress contributes to the learning and memory deficits during hyperglycemia [33]. In the current experiment, it was also found that MDA levels, as an index of lipid peroxidation, were increased in the hippocampal and cortical tissues of diabetic rats. Total thiol contents were also decreased in brain tissues of diabetic rats. These results confirmed the previous reports that streptozotocin-induced diabetes was accompanied by an increased generation of reactive species. It is also suggested 

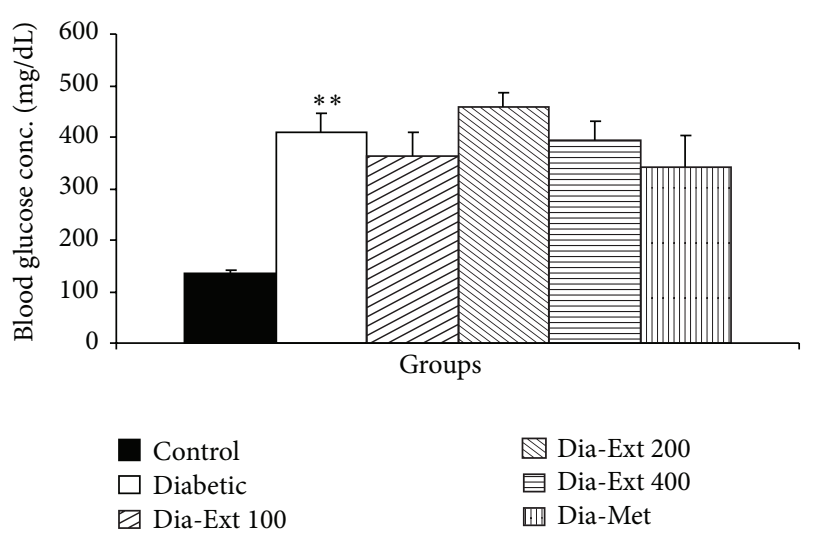

FIgURE 6: The blood glucose concentrations of 6 groups. Data are shown as mean \pm SEM of 10 animals per group. ${ }^{* *} P<0.01$ in comparison with Control group.

that the antioxidant compounds may have beneficial effects against the complications of diabetes mellitus [34-36].

The results of the present study showed that metformin improved learning and memory; it also reduced MDA concentration and increased total thiol groups in brain tissues of diabetic rats. In this study, we present evidence that metformin exerts an antioxidative effect, in vivo. This finding is in accordance with other studies which have shown that metformin treatment has antioxidant properties in STZdiabetic rats $[37,38]$. Similar observations have reported that metformin reduces oxidative stress in various animal models $[39,40]$. It has been previously suggested that metformin also has antioxidant activity which is independent of its effect on insulin activity [39]. In the current study, metformin had no significant effect on blood glucose levels in diabetic rats. It has been previously shown that metformin was not able to reduce the plasma levels of glucose in animal models with a high level of glucose similar to the present study [37]. In the present study, a lower dose of metformin $(300 \mathrm{mg} / \mathrm{kg})$ was used and it reduced blood glucose concentrations but the effect was not significant. It is reported that metformin reduces blood glucose level at much higher doses of $450-500 \mathrm{mg} / \mathrm{kg}$ in STZ-diabetic rats [41]. The results of human studies have also shown that metformin reduces the plasma glucose concentrations by approximately 20 to 30 percent and it has been suggested to be used in combination with other drugs [42]. Regarding the results of present study, it seems that the effects of metformin on learning and memory which were seen in the present study are probably independent of the effect on blood glucose level. Recently, metformin has been reported to improve microvascular function in type 2 diabetic models without improving hyperglycemia [43]. Sartoretto et al. (2005) have also reported that metformin increases nitric oxide activity in diabetic rats [43]. Nitric oxide is rapidly inactivated by $\mathrm{O}_{2}{ }^{-}$and it has been reported that enhanced formation of $\mathrm{O}_{2}^{-}$radical may be involved in the accelerated breakdown of nitric oxide [44]. Moreover, it has been shown that rapid destruction of nitric oxide occurs in diabetic rats [45]. The protective effect of metformin against oxidative stress may prevent the breakdown of nitric oxide, which may improve learning and memory tasks. Nitric oxide as a gaseous neurotransmitter has been shown to have an important role in learning and memory [46]. It has been previously reported that, when administered for 4 weeks, metformin lowered blood glucose level; however, these plasma glucose levels were still significantly higher than those of Control rats [38]. It has also been reported that metformin reduces vascular $\mathrm{O}_{2}{ }^{-}$ anion in aortic rings and the amounts of protein carbonyl compounds in serum of diabetic high-fat fed rats [38]. Several studies have reported the inhibitory effect of metformin on oxidative stress under various conditions: in vitro in either hyperglycemic or hyperlipidemic environments and in vivo [47-49]. Recently, it was reported that metformin may also diminish oxidative stress-related DNA damage [50]. Also, metformin treatment diminished the amounts of serum oxidized proteins and tissue lipid peroxides in diabetic rats [51]. The reduction of oxidative stress by metformin may partly be due to inhibition of glycation, a process that directly causes free-radical production. A recent study suggests that the intracellular antioxidant properties of metformin may result in the inhibition of both the advanced glycation end-products (AGEs) receptor and the lectin-like oxidized receptor [52].

In the present study, Teucrium polium hydroalcoholic extract prevented learning and memory impairments in diabetic rats. In accordance with the present study, it has been reported that Teucrium polium protects against memory impairments in scopolamine- and diabetes-induced memory impairment models [22, 53]. Teucrium polium has been reported to contain diterpenes and flavonoids [54]. The notable activity of Teucrium polium in memory augmentation could be related to its terpenic and flavonoid compounds [55]. The hypoglycemic effects of Teucrium polium have been previously reported $[12,14]$. In the present study the extract did not significantly reduce blood glucose level. Therefore, it seems that the beneficial effect of the extract on learning and memory impairments, which was seen in the present study, is not related to the blood glucose-lowering effect. In contrast to some reports which have suggested the blood glucose-lowering effects of Teucrium polium [14], there are also some reports which fail to confirm these effects $[12,56]$. Gharaibeh et al. reported that a decoction extract of the plant lowered the blood glucose by $20 \%$ similar to what was seen in the present study [12]. In another study, a percolated extract of the plant was not able to reduce the blood sugar in type II diabetic patients [56]. The discrepancies might be due to the type of extract. In the present study it was indicated that all three doses of Teucrium polium extract significantly reduced lipid peroxidation in the hippocampus and cerebral cortex. These marked protective effects of Teucrium polium against oxidative stress observed in this study are consistent with the previously published reports [57]. In this regard, a methanolic extract of Teucrium polium protected red blood cells against lipid peroxidation induced by hydrogen peroxide [58]. In another study, Panovska and coworkers [59] demonstrated that the extracts of Teucrium polium prepared using different organic solvents (diethyl ether, ethyl acetate, and n-butanol) were effective inhibitors of $\beta$-carotene oxidation. In another study, it was shown that the extracts prepared from Teucrium polium suppressed lipid peroxidation in vitro 
[60]. It is suggested that this high antioxidant activity is due to the phenolic compounds detected in this herb such as hydroxybenzoic acid derivatives, caffeic acid, ferulic acid, and flavonoid derivatives such as luteolin and quercetin [61]. It has been reported that Teucrium polium (200 and $400 \mathrm{mg} / \mathrm{kg}$ ) prevented the deleterious effects of diabetes on passive avoidance memory, but $100 \mathrm{mg} / \mathrm{kg}$ of Teucrium polium did not have any positive effect on the diabetesinduced memory deficits [22]. In the current study, memory deficits were prevented by all three doses of Teucrium polium $(100,200$, and $400 \mathrm{mg} / \mathrm{kg})$. On the other hand, we also indicated that all three doses of Teucrium polium significantly reduced lipid peroxidation in the hippocampus and cerebral cortex suggesting that protection against oxidative stress was probably involved in the learning and memory enhancing properties of the extract. The high dose of the extract also increased total thiol concentration in hippocampal tissues. In contrast to the beneficial effects of Teucrium polium which were mentioned and were seen in the present study, hepatotoxic and nephrotoxic effects of the plant have also been reported [62] and should be considered before reaching a final conclusion about the utility of this plant.

The role of oxidative stress in complications of diabetes has been studied extensively in experimental diabetes models and diabetic patients $[63,64]$. Due to the hyperglycemia associated with diabetes, enhanced formation of reactive oxygen occurs, which contributes to the increased neuronal death by oxidizing proteins, damaging DNA, and augmenting lipid peroxidation $[10,65]$. Oxidative damage to the rat synapse in the cerebral cortex and hippocampus has been previously reported to contribute to the deficit of cognitive functions $[8,66]$. Therefore, antioxidants might be of general use in the prevention of the neurodegeneration deficits and cognitive impairments associated with diabetes. The present study showed that treatment with Teucrium polium prevented the learning and memory deficits associated with STZinduced diabetes. The antioxidant property of Teucrium polium may reduce oxidative damage to the synapses in the hippocampus and cerebral cortex and therefore improve learning and memory deficits [66].

In general, it was found that Teucrium polium significantly ameliorated the cognitive impairment in diabetic rats. The exact mechanism of Teucrium polium in preventing learning and memory deficits is still in debate. In the current study, both oxidative stress and deficits in learning and memory induced by diabetes were prevented by the treatment with Teucrium polium suggesting that oxidative stress was probably involved in the diabetes-induced cognitive deficits which were prevented by Teucrium polium extract.

\section{Conflict of Interests}

The authors declare that there is no conflict of interests.

\section{Acknowledgment}

The authors would like to thank the Vice Presidency of Research, Mashhad University of Medical Sciences, for its financial support.

\section{References}

[1] S. Wild, G. Roglic, A. Green, R. Sicree, and H. King, "Global prevalence of diabetes: estimates for the year 2000 and projections for 2030," Diabetes Care, vol. 27, no. 5, pp. 1047-1053, 2004.

[2] A. L. McCall, "The impact of diabetes on the CNS," Diabetes, vol. 41, no. 5, pp. 557-570, 1992.

[3] W. H. Gispen and G.-J. Biessels, "Cognition and synaptic plasticity in diabetes mellitus," Trends in Neurosciences, vol. 23, no. 11, pp. 542-549, 2000.

[4] C. M. Ryan, "Neurobehavioral complications of type I diabetes. Examination of possible risk factors," Diabetes Care, vol. 11, no. 1, pp. 86-93, 1988.

[5] G. M. Reaven, L. W. Thompson, D. Nahum, and E. Haskins, "Relationship between hyperglycemia and cognitive function in older NIDDM patients," Diabetes Care, vol. 13, no. 1, pp. 16-21, 1990.

[6] P. A. Tun, D. M. Nathan, and L. C. Perlmuter, "Cognitive and affective disorders in elderly diabetics," Clinics in Geriatric Medicine, vol. 6, no. 4, pp. 731-746, 1990.

[7] R. Stewart and D. Liolitsa, "Type 2 diabetes mellitus, cognitive impairment and dementia," Diabetic Medicine, vol. 16, no. 2, pp. 93-112, 1999.

[8] K. Fukui, K. Onodera, T. Shinkai, S. Suzuki, and S. Urano, "Impairment of learning and memory in rats caused by oxidative stress and aging, and changes in antioxidative defense systems," Annals of the New York Academy of Sciences, vol. 928, pp. 168-175, 2001.

[9] G. Baydas, V. S. Nedzvetskii, P. A. Nerush, S. V. Kirichenko, and T. Yoldas, "Altered expression of NCAM in hippocampus and cortex may underlie memory and learning deficits in rats with streptozotocin-induced diabetes mellitus," Life Sciences, vol. 73, no. 15, pp. 1907-1916, 2003.

[10] C. L. Hawkins and M. J. Davies, "Generation and propagation of radical reactions on proteins," Biochimica et Biophysica ActaBioenergetics, vol. 1504, no. 2-3, pp. 196-219, 2001.

[11] E. M. Galati, M. R. Mondello, A. D’Aquino et al., "Effects of Teucrium divaricatum Heldr. ssp. divaricatum decoction on experimental ulcer in rats," Journal of Ethnopharmacology, vol. 72, no. 1-2, pp. 337-342, 2000.

[12] M. N. Gharaibeh, H. E. Elayan, and A. S. Salhab, "Hypoglycemic effects of teucrium polium," Journal of Ethnopharmacology, vol. 24, no. 1, pp. 93-99, 1988.

[13] M. Tariq, A. M. Ageel, M. A. Al-Yahya, J. S. Mossa, and M. S. Al-Said, "Anti-inflammatory activity of Teucrium polium," International Journal of Tissue Reactions, vol. 11, no. 4, pp. 185188, 1989.

[14] M. A. Esmaeili and R. Yazdanparast, "Hypoglycaemic effect of Teucrium polium: studies with rat pancreatic islets," Journal of Ethnopharmacology, vol. 95, no. 1, pp. 27-30, 2004.

[15] S. E. Mousavi, A. Shahriari, A. Ahangarpour, H. Vatanpour, and A. Jolodar, "Effects of Teucrium polium ethyl acetate extract on serum, liver and muscle triglyceride content of sucrose-induced insulin resistance in rat," Iranian Journal of Pharmaceutical Research, vol. 11, no. 1, pp. 347-355, 2012.

[16] S. Niazmand, M. Esparham, T. Hassannia, and M. Derakhshan, "Cardiovascular effects of Teucrium polium L. extract in rabbit," Pharmacognosy Magazine, vol. 7, no. 27, pp. 260-264, 2011.

[17] M.-S. Suleiman, A.-S. Abdul-Ghani, S. Al-Khalil, and R. Amin, "Effect of Teucrium polium boiled leaf extract on intestinal motility and blood pressure," Journal of Ethnopharmacology, vol. 22, no. 1, pp. 111-116, 1988. 
[18] H. R. Rasekh, M. J. Khoshnood-Mansourkhani, and M. Kamalinejad, "Hypolipidemic effects of Teucrium polium in rats," Fitoterapia, vol. 72, no. 8, pp. 937-939, 2001.

[19] M. Abdollahi, H. Karimpour, and H. R. Monsef-Esfehani, "Antinociceptive effects of Teucrium polium L. total extract and essential oil in mouse writhing test," Pharmacological Research, vol. 48, no. 1, pp. 31-35, 2003.

[20] M. Couladis, O. Tzakou, E. Verykokidou, and C. Harvala, "Screening of some Greek aromatic plants for antioxidant activity," Phytotherapy Research, vol. 17, no. 2, pp. 194-195, 2003.

[21] H. Kalantari, H. Forouzandeh, M. E. Azemi, I. Rashidi, and M. Goudarzi, "Study of the protective effect of Teucrium polium L. extract on acetaminophen-induced hepatotoxicity in mice," Iranian Journal of Pharmaceutical Research, vol. 12, no. 1, pp. 123-129, 2013.

[22] P. Hasanein and S. Shahidi, "Preventive effect of Teucrium polium on learning and memory deficits in diabetic rats," Medical Science Monitor, vol. 18, no. 1, pp. BR41-BR46, 2012.

[23] Z. Rajaei, M.-A. Hadjzadeh, H. Nemati, M. Hosseini, M. Ahmadi, and S. Shafiee, "Antihyperglycemic and antioxidant activity of crocin in streptozotocin-induced diabetic rats," Journal of Medicinal Food, vol. 16, no. 3, pp. 206-210, 2013.

[24] S. Taleb, P. Moghaddas, M. Rahimi Balaei et al., "Metformin improves skin flap survival through nitric oxide system," Journal of Surgical Research, vol. 192, no. 2, pp. 686-691, 2014.

[25] S. M. Naghibi, M. Hosseini, F. Khani et al., "Effect of aqueous extract of Crocus sativus L. on morphine-induced memory impairment," Advances in Pharmacological Sciences, vol. 2012, Article ID 494367, 7 pages, 2012.

[26] G. L. Ellman, “Tissue sulfhydryl groups," Archives of Biochemistry and Biophysics, vol. 82, no. 1, pp. 70-77, 1959.

[27] M. Hosseini, M. Pourganji, F. Khodabandehloo, M. Soukhtanloo, and H. Zabihi, "Protective effect of L-Arginine against oxidative damage as a possible mechanism of its beneficial properties on spatial learning in ovariectomized rats," Basic and Clinical Neuroscience, vol. 3, no. 5, pp. 36-44, 2012.

[28] F. Khodabandehloo, M. Hosseini, Z. Rajaei, M. Soukhtanloo, E. Farrokhi, and M. Rezaeipour, "Brain tissue oxidative damage as a possible mechanism for the deleterious effect of a chronic high dose of estradiol on learning and memory in ovariectomized rats," Arquivos de Neuro-Psiquiatria, vol. 71, no. 5, pp. 313-339, 2013.

[29] G.-J. Biessels, A. Kamal, G. M. Ramakers et al., "Place learning and hippocampal synaptic plasticity in streptozotocin-induced diabetic rats," Diabetes, vol. 45, no. 9, pp. 1259-1266, 1996.

[30] M. W. J. Strachan, B. M. Frier, and I. J. Deary, “Type 2 diabetes and cognitive impairment," Diabetic Medicine, vol. 20, no. 1, pp. $1-2,2003$.

[31] A. J. Sommerfield, I. J. Deary, and B. M. Frier, "Acute hyperglycemia alters mood state and impairs cognitive performance in people with type 2 diabetes," Diabetes Care, vol. 27, no. 10, pp. 2335-2340, 2004.

[32] G.-J. Biessels, A. Kamal, I. J. A. Urban, B. M. Spruijt, D. W. Erkelens, and W. H. Gispen, "Water maze learning and hippocampal synaptic plasticity in streptozotocin-diabetic rats: effects of insulin treatment," Brain Research, vol. 800, no. 1, pp. 125-135, 1998.

[33] E. Tamaddonfard, A. A. Farshid, S. Asri-Rezaee et al., "Crocin improved learning and memory impairments in streptozotocin-induced diabetic rats," Iranian Journal of Basic Medical Sciences, vol. 16, no. 1, pp. 91-100, 2013.
[34] G. Baydas, H. Canatan, and A. Turkoglu, "Comparative analysis of the protective effects of melatonin and vitamin E on streptozocin-induced diabetes mellitus," Journal of Pineal Research, vol. 32, no. 4, pp. 225-230, 2002.

[35] S. Celik, G. Bayda, and O. Ylmaz, "Influence of vitamin E on the levels of fatty acids and MDA in some tissues of diabetic rats," Cell Biochemistry \& Function, vol. 20, no. 1, pp. 67-71, 2002.

[36] G. Baydas, E. Sonkaya, M. Tuzcu, A. Yasar, and E. Donder, "Novel role for gabapentin in neuroprotection of central nervous system in streptozotocine-induced diabetic rats," Acta Pharmacologica Sinica, vol. 26, no. 4, pp. 417-422, 2005.

[37] J. B. Majithiya and R. Balaraman, "Metformin reduces blood pressure and restores endothelial function in aorta of streptozotocin-induced diabetic rats," Life Sciences, vol. 78, no. 22, pp. 2615-2624, 2006.

[38] C. M. Sena, P. Matafome, T. Louro, E. Nunes, R. Fernandes, and R. M. Seiça, "Metformin restores endothelial function in aorta of diabetic rats," British Journal of Pharmacology, vol. 163, no. 2, pp. 424-437, 2011.

[39] P. Faure, E. Rossini, N. Wiernsperger, M. J. Richard, A. Favier, and S. Halimi, "An insulin sensitizer improves the free radical defense system potential and insulin sensitivity in high fructose-fed rats," Diabetes, vol. 48, no. 2, pp. 353-357, 1999.

[40] D. Bonnefont-Rousselot, B. Raji, S. Walrand et al., "An intracellular modulation of free radical production could contribute to the beneficial effects of metformin towards oxidative stress," Metabolism, vol. 52, no. 5, pp. 586-589, 2003.

[41] D. Stepensky, M. Friedman, I. Raz, and A. Hoffman, "Pharmacokinetic-pharmacodynamic analysis of the glucose-lowering effect of metformin in diabetic rats reveals first-pass pharmacodynamic effect," Drug Metabolism and Disposition, vol. 30, no. 8, pp. 861-868, 2002.

[42] C. J. Bailey and R. C. Turner, "Metformin," The New England Journal of Medicine, vol. 334, no. 9, pp. 574-579, 1996.

[43] J. L. Sartoretto, G. A. N. Melo, M. H. C. Carvalho et al., "Metformin treatment restores the altered microvascular reactivity in neonatal streptozotocin-induced diabetic rats increasing NOS activity, but not NOS expression," Life Sciences, vol. 77, no. 21, pp. 2676-2689, 2005.

[44] G. M. Rubanyi, J. C. Romero, and P. M. Vanhoutte, "Flowinduced release of endothelium-derived relaxing factor," The American Journal of Physiology-Heart and Circulatory Physiology, vol. 250, no. 6, pp. H822-H827, 1986.

[45] K. Kamata and T. Kobayashi, "Changes in superoxide dismutase mRNA expression by streptozotocin-induced diabetes," British Journal of Pharmacology, vol. 119, no. 3, pp. 583-589, 1996.

[46] R. Sadeghian, M. Fereidoni, M. Soukhtanloo, H. AziziMalekabadi, and M. Hosseini, "Decreased nitric oxide levels in the hippocampus may play a role in learning and memory deficits in ovariectomized rats treated by a high dose of estradiol," Arquivos de Neuro-Psiquiatria, vol. 70, no. 11, pp. 874879, 2012.

[47] P. Gargiulo, D. Caccese, P. Pignatelli et al., "Metformin decreases platelet superoxide anion production in diabetic patients," Diabetes/Metabolism Research and Reviews, vol. 18, no. 2, pp. 156-159, 2002.

[48] C. Bellin, D. H. De Wiza, N. F. Wiernsperger, and P. Rösen, "Generation of reactive oxygen species by endothelial and smooth muscle cells: influence of hyperglycemia and metformin," Hormone and Metabolic Research, vol. 38, no. 11, pp. 732-739, 2006. 
[49] C. J. Bailey, C. Wilcock, and J. H. B. Scarpello, "Metformin and the intestine," Diabetologia, vol. 51, no. 8, pp. 1552-1553, 2008.

[50] G. Kanigür-Sultuybek, Ş. B. Ozdas, A. Curgunlu, V. Tezcan, and I. Onaran, "Does metformin prevent short-term oxidantinduced DNA damage? In vitro study on lymphocytes from aged subjects," Journal of Basic and Clinical Physiology and Pharmacology, vol. 18, no. 2, pp. 129-140, 2007.

[51] P. Rösen and N. F. Wiernsperger, "Metformin delays the manifestation of diabetes and vascular dysfunction in Goto-Kakizaki rats by reduction of mitochondrial oxidative stress," Diabetes/Metabolism Research and Reviews, vol. 22, no. 4, pp. 323330, 2006.

[52] N. Ouslimani, M. Mahrouf, J. Peynet et al., "Metformin reduces endothelial cell expression of both the receptor for advanced glycation end products and lectin-like oxidized receptor 1," Metabolism: Clinical and Experimental, vol. 56, no. 3, pp. 308313, 2007.

[53] I. Orhan and M. Aslan, "Appraisal of scopolamine-induced antiamnesic effect in mice and in vitro antiacetylcholinesterase and antioxidant activities of some traditionally used Lamiaceae plants," Journal of Ethnopharmacology, vol. 122, no. 2, pp. 327332, 2009.

[54] R. Alcázar, M. C. De la Torre, B. Rodríguez et al., "Neoclerodane diterpenoids from three species of Teucrium," Phytochemistry, vol. 31, no. 11, pp. 3957-3960, 1992.

[55] S. Bahramikia and R. Yazdanparast, "Phytochemistry and medicinal properties of Teucrium polium L. (Lamiaceae)," Phytotherapy Research, vol. 26, no. 11, pp. 1581-1593, 2012.

[56] A. Ansari Asl, M. Soveid, M. Azadbakht, G. R. Omrani, S. M. Solimani, and M. Samani, "The effect of extract of Teucrium polium on blood sugar and insulin levels of type 2 diabetic patients," Shiraz Medical Journal, vol. 1, no. 1, pp. 1-5, 2000.

[57] P. Ljubuncic, S. Dakwar, I. Portnaya, U. Cogan, H. Azaizeh, and A. Bomzon, "Aqueous extracts of Teucrium polium possess remarkable antioxidant activity in vitro," Evidence-Based Complementary and Alternative Medicine, vol. 3, no. 3, pp. 329-338, 2006.

[58] S. M. Suboh, Y. Y. Bilto, and T. A. Aburjai, "Protective effects of selected medicinal plants against protein degradation, lipid peroxidation and deformability loss of oxidatively stressed human erythrocytes," Phytotherapy Research, vol. 18, no. 4, pp. 280-284, 2004.

[59] T. K. Panovska, S. Kulevanova, and M. Stefova, "In vitro antioxidant activity of some Teucrium species (Lamiaceae)," Acta Pharmaceutica, vol. 55, no. 2, pp. 207-214, 2005.

[60] K. I. Qabaha, "Antimicrobial and free radical scavenging activities of five Palestinian medicinal plants," African Journal of Traditional, Complementary and Alternative Medicines, vol. 10, no. 4, pp. 101-108, 2013.

[61] C. Proestos, D. Sereli, and M. Komaitis, "Determination of phenolic compounds in aromatic plants by RP-HPLC and GCMS," Food Chemistry, vol. 95, no. 1, pp. 44-52, 2006.

[62] M. Rafieian-Kopaei and H. Nasri, "Comment on: preventive effect of Teucrium polium on learning and memory deficits in diabetic rats," Medical Science Monitor Basic Research, vol. 19, pp. 208-209, 2013.

[63] J. W. Baynes, "Role of oxidative stress in development of complications in diabetes," Diabetes, vol. 40, no. 4, pp. 405-412, 1991.

[64] A. Lapolla and D. Fedele, "Oxidative stress and diabetes: role in the development of chronic complications," Minerva Endocrinologica, vol. 18, no. 3, pp. 99-108, 1993.
[65] C. Luxford, R. T. Dean, and M. J. Davies, "Radicals derived from histone hydroperoxides damage nucleobases in RNA and DNA," Chemical Research in Toxicology, vol. 13, no. 7, pp. 665$672,2000$.

[66] K. Fukui, N.-O. Omoi, T. Hayasaka et al., "Cognitive impairment of rats caused by oxidative stress and aging, and its prevention by vitamin E," Annals of the New York Academy of Sciences, vol. 959, pp. 275-284, 2002. 


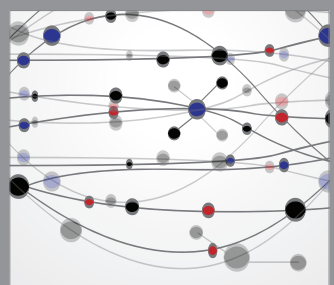

The Scientific World Journal
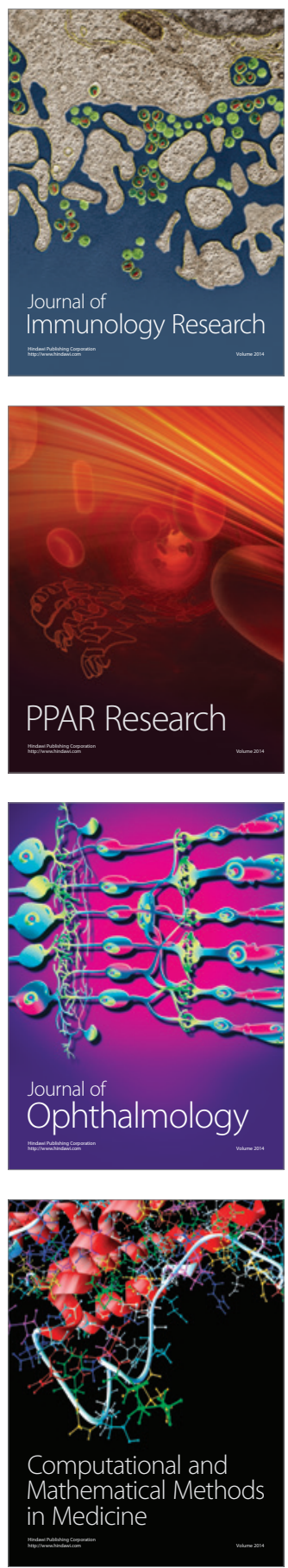

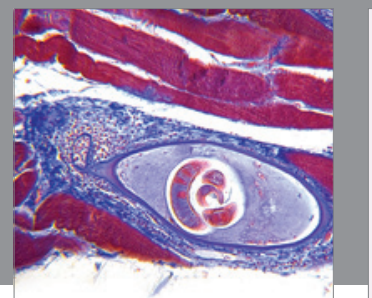

Gastroenterology

Research and Practice
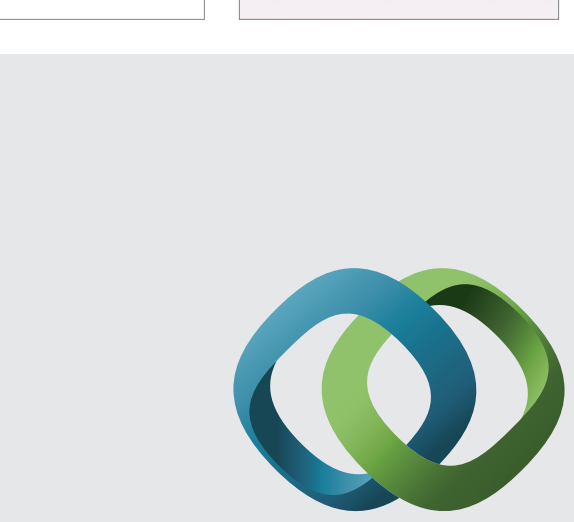

\section{Hindawi}

Submit your manuscripts at

http://www.hindawi.com
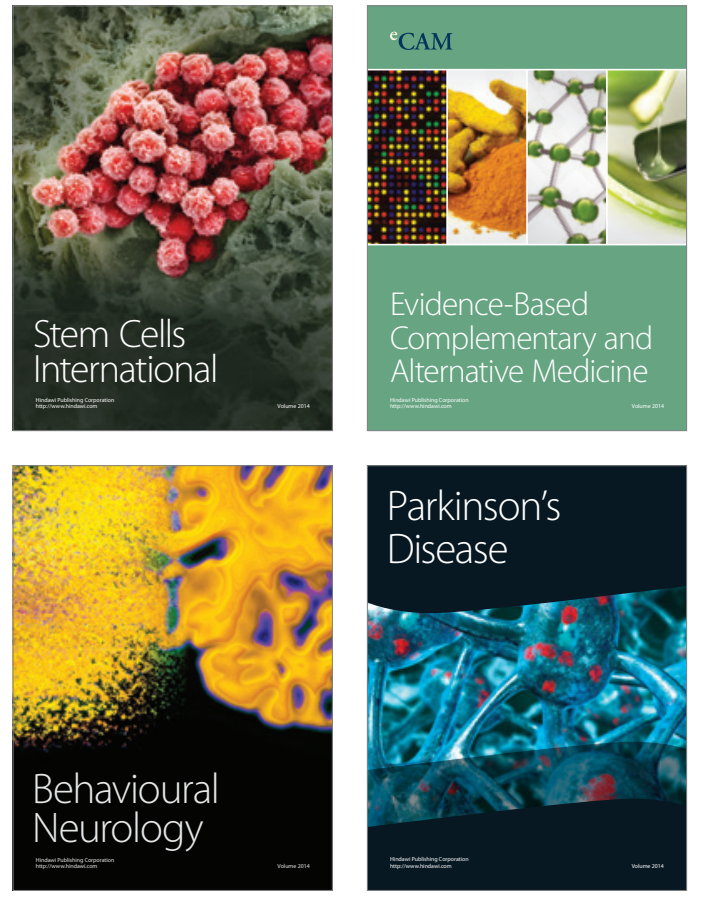
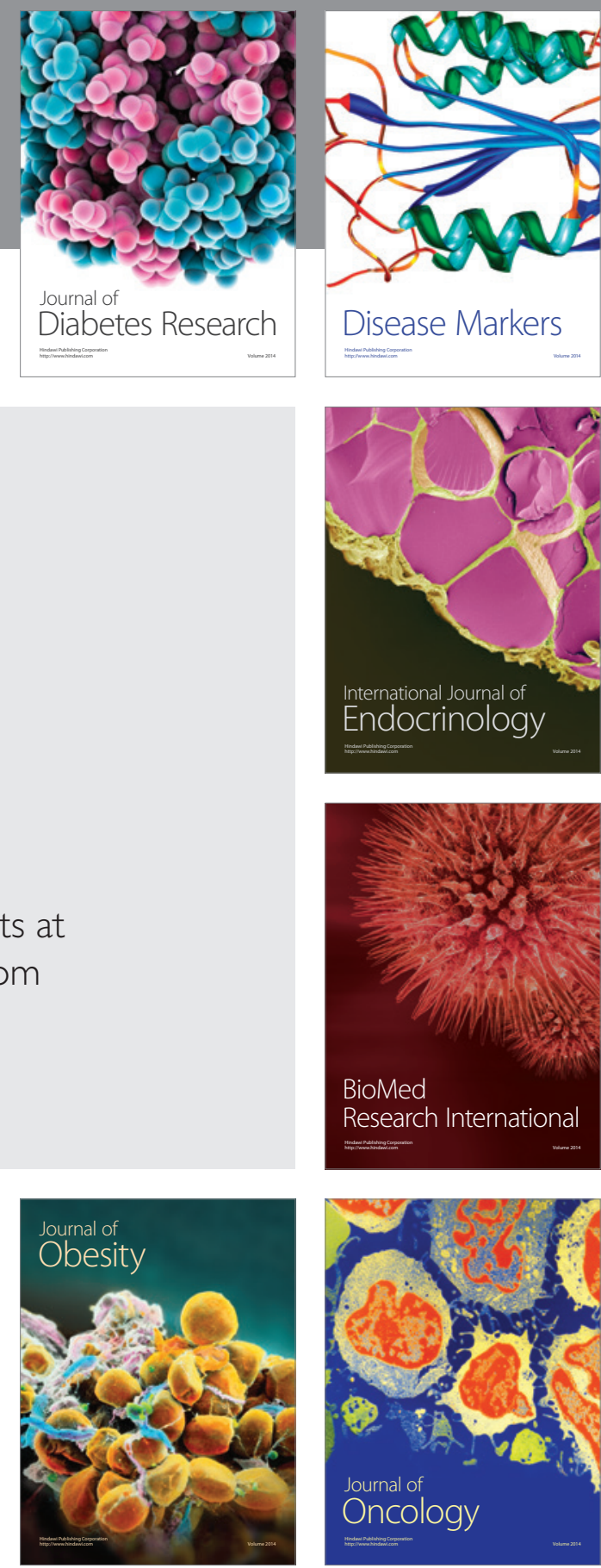

Disease Markers
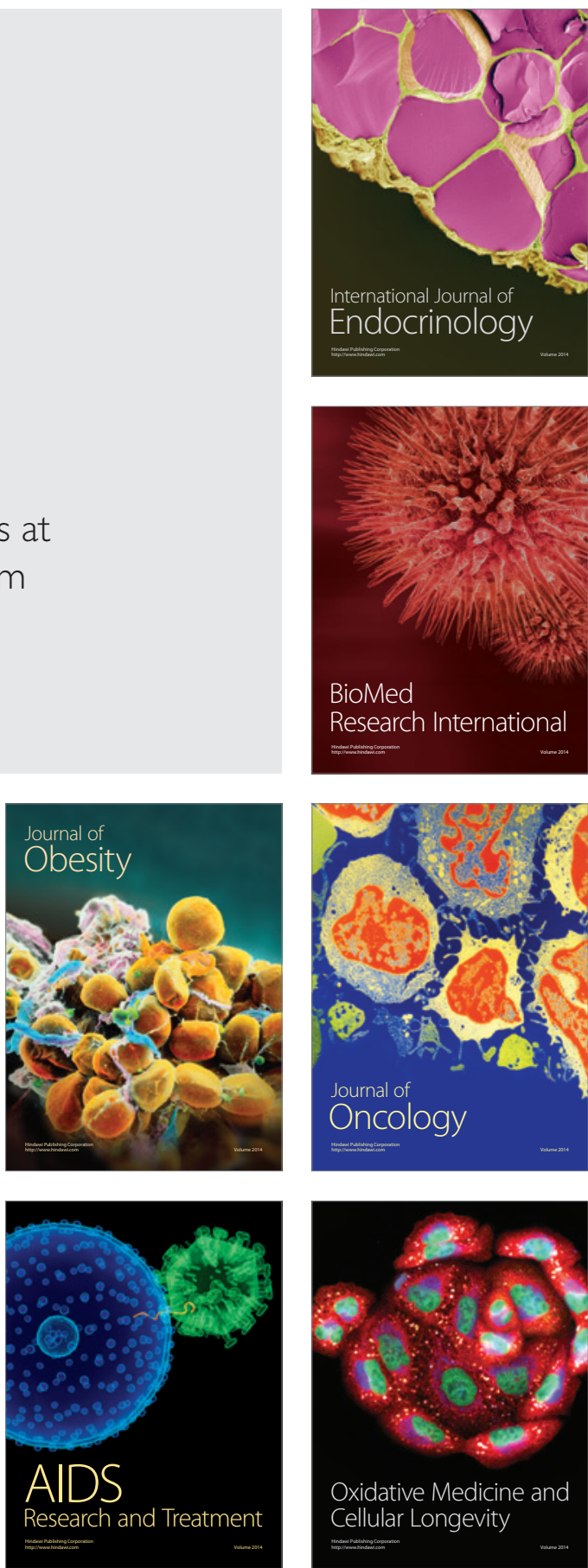